\title{
La carta a los Filipenses como un documento salido de la prisión
}

\section{Elsa Tamez}

No hay duda de que Pablo escribió la carta a los Filipenses desde una prisión ${ }^{1}$. Había sido encarcelado por sus ideas, por el evangelio, no por tener deudas o ser un criminal. Sin embargo, poco se toma en serio esta situación particular de Pablo. Para nosotros, esta realidad es vital, porque, según nuestra lectura, el hecho de que escriba desde la cárcel, en espera de una probable condena a muerte $(1,20)$, condiciona todo el discurso de la carta. Podemos afirmar que la prisión es el lugar (locus) teológico desde donde reflexiona su visión cristológica.

El ensayo tiene dos partes: la primera reconstruye el escenario del apóstol Pablo en la cárcel. Esto implica analizar las prisiones, las cadenas de la antigüedad, los cargos y las implicaciones de escribir cartas desde la prisión. La segunda parte está dedicada a releer algunos aspectos de la carta desde este ángulo, como la situación física y emocional de Pablo encadenado, y a reflexionar sobre la teología que surge de la prisión y sobre las exhortaciones a sus destinatarios, condicionadas por ese contexto.

\section{Estar en la cárcel: implicaciones}

Contamos con escasísima literatura sobre cartas antiguas no bíblicas y salidas de la prisión. Existen algunos papiros que no ayudan mucho. También hay testimonios valiosos de algunos prisioneros del siglo I y afirmaciones de historiadores de la antigüedad sobre la situación de las cárceles.

Craig S. Wansink, en su libro Chained in Christ, hace un excelente análisis sobre la situación de las cárceles antiguas y los prisioneros ${ }^{2}$. Si bien, tal como él indica, arqueológicamente hay poca evidencia sobre las prisiones antiguas, existe

1. Buena parte de este artículo fue publicado como "La carta de Pablo a los Filipenses desde la perspectiva de un prisionero político", Revista Bíblica 3.4 (2012), 193-217.

2. C. S. Wansink, Chained in Christ. The Experience and Rhetoric of Paul's Imprisonments (Sheffield: Sheffield Academic Press, 1996), pp. 33-40. 
suficiente evidencia de fuentes literarias que apuntan a lo mismo: la cárcel era un espacio reducido, abarrotado de prisioneros, con poco aire, bastante oscuro y asqueroso y, por lo tanto, dañino para la salud, donde las enfermedades abundaban.

Los sufrimientos en las prisiones eran muchos. Además de las malas condiciones, como el espacio sucio, oscuro y falto de aire, donde se hacía difícil respirar, los detenidos padecían torturas físicas, como golpes y azotes, y torturas mentales, como insultos y amenazas. Estar encadenado no era raro. Tenemos el caso de Antiphilus, que dormía en el suelo y de noche le ponían cadenas en los pies, mientras que de día usaba un collar de hierro alrededor del cuello y grilletes en el brazo o en la mano (manacle). Difícilmente dormía, no solo por la incomodidad, sino también por el ruido de las cadenas de hierro de los prisioneros. Experimentó tal cambio físico que su amigo Demetrio, cuando fue a verlo, no lo pudo reconocer ${ }^{3}$.

En algunos casos, las condiciones eran tan terribles que morir era una salida más digna. Según las investigaciones de Wansink y de Cassidy, muchos romanos prefirieron el suicidio ${ }^{4}$ a seguir viviendo la humillación de la cárcel. Wansink, basándose en Dio y Suetonio, afirma que en algunos casos la ejecución se retrasaba para que el prisionero sufriera más tiempo ${ }^{5}$.

En cuanto a la cantidad de prisioneros y al tamaño de las cárceles, no hay muchos datos, pero un relato habla de un espacio donde cabían nueve colchones y había 50 prisioneros $^{6}$.

Estos sufrimientos, descritos en fuentes extra bíblicas, los encontramos también en Hechos. Tal como mencionamos antes, Pablo fue arrestado en Filipos por perjudicar el negocio de los explotadores de una niña adivina. Fue denunciado, llevado a los tribunales y allí fue desnudado, azotado, echado a la cárcel, asegurado con un cepo en los pies y colocado en la parte más horrenda de la prisión, la parte interior (16,22-24). A esta habitación también se refieren las fuentes extra bíblicas.

A través de esas fuentes literarias se deduce que había un espacio o habitación interior dentro de la prisión. En los estudios de Wansink queda claro que no había celdas individuales, sino que todos los prisioneros estaban juntos y encade-

3. Ibid., p. 36 .

4. R. Cassidy, Paul in Chains. Roman Imprisonment and the Letters of St. Paul (New York: A Herder ad Herder Book, The Crossroad Publishing Co., 2001), p. 46.

5. Los historiadores cuentan el caso de un prisionero que suplicó al emperador Tiberio que lo ejecutaran de inmediato, pero el emperador le respondió: "Aún no soy tu amigo". C. S. Wansink, Chained in Christ, o. c. p. 32.

6. R. Cassidy, Paul in Chains, o. c., p. 38. Se trata del relato de Diodoro sobre el prisionero Perseo, detenido en la prisión de Alba Fucens (Diodorus, Library of History, 31.9.1-14). 
nados, en el mismo espacio. En la parte más baja de la prisión había una habitación que, según los testimonios, era el lugar más temible y más oscuro. Allí eran enviados aquellos prisioneros castigados o aislados por razones de seguridad. Wansink señala cómo varios mártires cristianos fueron mandados a ese cuarto interior por distintas razones. Algunos por no pagar soborno a los carceleros, como fue el caso de Pionius ${ }^{7}$. Se trata justamente de este cuarto, ubicado en la parte más baja del presidio, más de tres metros y medio por debajo del nivel del suelo de la cárcel, según lo indica el historiador romano Salustio (86-35 a. C.) ${ }^{8}$. En la antigüedad, esa celda o cuarto era llamado Tullianum ${ }^{9}$.

Richard Cassidy, en su conocido libro Paul in Chains, aclara que la severidad del encarcelamiento dependía del tipo de custodia asignado. La ley estableció tres tipos ${ }^{10}$. La más cruel era la cárcel (carcer) propiamente dicha, le seguía la llamada custodia militar (custodia militaris) y después la custodia libre (custodia libera) ${ }^{11}$. De la cárcel ya se habló aquí. La custodia militar consistía en encadenar al prisionero a uno o dos soldados, que lo custodiaban bajo la dirección de un centurión. La mayoría de los estudiosos están de acuerdo en afirmar que Pablo sufrió la custodia militar, muy parecida a la de Herodes Agripa I, narrada por Josefo. A través de la narración del historiador, se infiere que no era fácil contar con baño diario y que los soldados a los cuales el prisionero estaba encadenado podían hacerle la vida imposible. El sobrellevar la carga de la prisión dependía mucho del carácter del soldado al cual el prisionero permanecía encadenado todo el día. Los prisioneros en custodia militar podían recibir visitas y recibir obsequios, como alimentos y ropa. El peso del hierro hace que las cadenas resulten muy incómodas para el prisionero. Las cadenas se empleaban para los brazos y las manos (manacles) y para las piernas y los pies (pedicles) ${ }^{12}$.

El buen o mal trato también dependía del estatuto del preso. Regularmente, como es de esperar, el trato no es igual, pues el prisionero con influencia, poder y riqueza es mejor tratado. Las leyes de iure y de facto evidencian el prejuicio y la parcialidad de los jueces y los oficiales romanos ${ }^{13}$.

El encarcelamiento de Pablo, según podemos observar en Filemón y Filipenses, es más bien de este tipo y no una custodia libera, según Hechos 28,30-31. La custodia libre, reservada a las élites, permitía estar no encadenado

7. C. S. Wansink, Chained in Christ, o. c., p. 37.

8. En La conjuración de Catilina (Madrid: Espasa-Calpe, 1986 ${ }^{8}$ ).

9. C. S. Wansink, Chained in Christ, o. c., p. 40.

10. En tiempos del emperador Justiniano, muchos años después, pero seguramente ya existían estas modalidades en la época de Pablo. Lo deducimos por testimonios bíblicos y extrabíblicos.

11. R. Cassidy, Paul in Chains, o. c., p. 37.

12. Ibid., p. 46.

13. E. Tamez, Contra toda condena (San José: DEI, 1991), p. 63. 
y ser supervisado por un miembro de la familia ${ }^{14}$. Pablo, un artesano no perteneciente a la clase senatorial, ni ecuestre, ni a la clase aristocrática de la provincia, podía no sufrir el primer tipo de cárcel, pero difícilmente podría haber sido un prisionero en custodia libre ${ }^{15}$. La custodia militar era menos cruel que la cárcel, pero eso no elimina el sufrimiento que padeció Pablo bajo la custodia militar, esto es, vigilado por soldados y encadenado permanentemente a ellos. Siendo así, Pablo dependía del humor y del carácter o temperamento del soldado o de los soldados a los cuales estaba atado, una situación nada fácil. Permanecer encadenado a uno o dos soldados significaba vergüenza y humillación ${ }^{16}$, algo grave en una cultura regida por los patrones del honor y de la vergüenza. La custodia militar era común en el tiempo de Pablo ${ }^{17}$. En 2 Timoteo 1,16, el autor agradece que Onesíforo no se haya avergonzado de sus cadenas; mientras que Figelo y Hermógenes lo habían abandonado. Esto nos lleva a concluir que Pablo no exagera cuando con crudeza describe a los Corintios su terrible experiencia en la prisión de Asia (2 Co 1,8-10). Asimismo, pensamos que sus escritos, de alguna forma, están condicionados por su situación vital en el momento de redactarlos.

A propósito de Onesíforo (2 Tim 1,16) y de los filipenses, que socorrieron asiduamente a Pablo en la prisión, debemos recordar que la situación de los prisioneros en cuanto a alimentos, ayudas económicas y apoyo moral era de vital importancia. En su carta a los Filipenses, Pablo no oculta su gran alegría al recibir la ayuda que la comunidad de Filipos le ha brindado, a través de Epafrodito. Los familiares y amigos hacían la situación en cadenas un poco más tolerable al proporcionarles comida y ropa, y el consuelo de permanecer cerca para conversar y ayudarles a preparar su defensa (2 Tim 4,16). En los orígenes del cristianismo, los cristianos detenidos tenían la ventaja de contar con hermanos y hermanas de la ekklesia, que se encargaban de atenderlos. Contamos con varias cartas bíblicas y extra bíblicas, que relatan la asistencia de los hermanos a los prisioneros por la causa de Cristo. En el ámbito bíblico, la carta de Pablo a Filemón menciona la compañía y colaboración de Marcos, Aristarco, Dimas y Lucas, además de Timoteo y Onésimo. Lo mismo observamos en Filipenses, pues el apóstol tiene el gran apoyo de Timoteo (2,19-24), además de Epafrodito (4,10-19; 2,30), que llega desde Filipos, enviado por las comunidades, para llevarle ayuda económica y para asistirlo.

También se da el caso contrario: el abandono al prisionero. El autor de 2 Timoteo, prisionero en Roma (1,17), escribe que Dimas lo ha dejado (2 Tim 4,10),

14. R. Cassidy, Paul in Chains, o. c., p. 42.

15. A. Standhartinger, "Aus der Welt eines Gefangenen. Die Kommunikationsstruktur des Philipperbriefs im Spiegel seiner Abfassungssituation”, Novum Testamentum 55 (2013), 142-143.

16. R. Cassidy, Paul in Chains, o. c., p. 48; 2 Tim 1,8.

17. R. Cassidy, Paul in Chains, o. c. 
junto con otros de Asia (Figelo y Hermógenes), excepto por Onesífero, pues se han avergonzado de sus cadenas.

Una cuestión importante son los cargos contra los prisioneros. Los delitos comunes, por lo que sabemos, eran hurto, daños a terceros, deudas, ultrajes, etc. También había delitos públicos, como los de subversión (seditio) o traición al emperador, llamado maiestas en latín. Según algunos estudiosos, Pablo fue probablemente encarcelado por sedición o por traición al emperador (maiestas), que es casi lo mismo ${ }^{18}$. Esta acusación, según Cassidy, "en sus orígenes era un cargo contra aquellos metidos en actividades subversivas, como revueltas militares o por colaborar con el enemigo" 19 . Pero más tarde se convirtió en "cualquier tipo de conducta que dañaba la majestad del pueblo romano", es decir, del emperador. Ahora bien, siempre de acuerdo con Cassidy, el cargo de conspiración real luego sirvió de pretexto para encarcelar a cualquiera. Bastaba un pequeño detalle o gesto difamatorio contra el emperador para ser detenido, acusado de conspiración. El cambio ocurre en tiempos de Augusto, cuando se incluye la difamación en la lex maiestas ${ }^{20}$. El abuso es mayor en tiempos del emperador Tiberio y, sobre todo, de Nerón. Pablo vivió justamente en la época de Nerón.

\section{Escribir desde la cárcel: implicaciones}

Poca atención se ha dado a lo que significa escribir desde la prisión ${ }^{21}$. Los debates se concentran más en el lugar geográfico desde donde escribe Pablo su carta a los Filipenses: si desde Éfeso, Roma o Cesarea. Sin embargo, pese a la importancia de tener en mente un lugar geográfico, más importante es visualizar el espacio físico de la prisión, donde el autor escribe la carta. Es decir, conviene tener en cuenta las dificultades, los riesgos, la censura y las consecuencias de la interceptación de una carta. Por eso, la pregunta para Angela Standhartinger es averiguar cómo eran las estructuras de comunicación con las que lidiaban las personas detenidas en aquellos tiempos. Para ella, es importante saber cómo se podía escribir, qué se podía decir en un ambiente de vigilancia extrema y de

18. Ibid., pp. 55-67. No hay plena seguridad al respecto. Hechos habla de tumultos causados por la predicación de Pablo, los cuales provocaron el arresto. Pero algunas de las acusaciones son muy comprometedoras, como la de Tesalónica, cuando fue denunciado por violentar los decretos del emperador y por afirmar que había otro rey (Hch 17,7).

19. R. Cassidy, Paul in Chains, o. c., p. 56.

20. N. Santos Yanguas, "Acusaciones de alta traición en Roma en la época de Tiberio" (Universidad de Oviedo: Dialnet).

21. A. Standhartinger, "Aus der Welt eines Gefangenen", o. c., p. 143. La autora estudia las condiciones de las prisiones, los riesgos y las estrategias de quienes escriben, y los problemas de la recepción de la carta, lo cual incluye los riesgos y la tarea de decodificar su discurso. 
censura. Está claro que el escrito no llega primero a sus destinatarios, sino que antes pasa por las manos de los guardias, los jueces ${ }^{22}$ y otros vigilantes. Según la autora, el discurso de Pablo considera esos riesgos y, por lo tanto, su escrito posee necesariamente cierta dosis de ambigüedad. Por otro lado, es necesario tomar en cuenta que los destinatarios de la carta, es decir, la comunidad cristiana de Filipos, tendría que saber interpretar lo que el apóstol intentaba decirles en su carta. Esto significa, entre otras cosas, que debía leer entre líneas y distinguir dos discursos, el público y el oculto.

Escribir en la prisión era peligroso. Hay testimonios de muertes debidas a las interpretaciones que los responsables hicieron de algunos escritos que, según ellos, hablaban contra el emperador ${ }^{23}$. La vigilancia era permanente y no era extraño que hubiera espías, enviados por el césar para recabar información sobre actitudes contrarias a él. Tiberio y Nerón eran muy susceptibles a las críticas, por lo cual se abusaba del delito de maiestas. Augusto, señala Standhartinger, tendió una red de seguridad interna, una especie de policía secreta de Roma. El espionaje también ocurría en las provincias, a través de los gobernadores. Al igual que los tiempos de represión de las dictaduras modernas, había una lista de personas sospechosas. Se daba el caso de soldados que, vestidos de civil, iniciaban conversaciones contra el emperador para ver si su interlocutor caía en la trampa y hablaba mal del emperador, en cuyo caso lo arrestaban, lo llevaban a la cárcel y lo encadenaban ${ }^{24}$.

Por esa razón, los documentos escritos en la prisión tenían que ser muy cuidadosos para no prestarse a interpretaciones sediciosas o para no ser acusados de críticas al emperador. Los mensajes ocultos, ambiguos y con vacíos no son raros. Tampoco los seudónimos e incluso era preferible escribir en otro idioma distinto del latín ${ }^{25}$. Según Standhartinger:

Dado que las cartas corrían el peligro de ser leídas incluso por perseguidores, se hicieron intentos para oscurecer su contenido. En la antigüedad ya se contaba con sistemas de escritura secreta y criptográfica. Las técnicas de ocultamiento incluían la elaboración de un contenido tan opaco como fuera posible, usaban seudónimos, juegos de palabras, acertijos o escribían en otro idioma. ${ }^{26}$

22. Ibid., p. 145.

23. Ibid., p. 156.

24. Ibid., p. 157.

25. Ibid., p. 158.

26. Ibidem. La traducción es mía. La autora incluye la siguiente cita de Cicerón, escrita a su amigo Atticus: "Pero escribo esto apurado, y ciertamente tengo miedo de decir demasiado. En las próximas cartas escribiré todo con claridad, si encuentro un mensajero totalmente confiable, o si no, si escribo oscuramente, ustedes entenderán a pesar de todo. En esas cartas tomaré el nombre de Laelius y tú, Furius. El resto

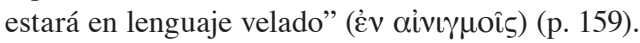


Filipenses es una carta escrita desde la prisión por un detenido que experimenta una gran incertidumbre frente a su juicio y condena, una situación de vida o muerte. El análisis de su discurso no puede pasar por alto esta realidad.

Por otro lado, esas circunstancias también tenían implicaciones para los destinatarios, pues las frases, las palabras y los nombres podrían comprometerlos. $\mathrm{Y}$ es que, como lo indica Standhartinger, estar en contacto con los prisioneros considerados subversivos era también arriesgado. No solo porque tener un amigo o un familiar en prisión era vergonzoso, sino también porque la comunicación era vigilada por las autoridades. Los espías de la policía secreta romana estaban presentes en todos lados. Por eso, en la comunicación de mensajes había que ser precavido. Cualquier cosa sospechosa que se dijera podía ser utilizada en contra de su autor. Llama la atención que en los inicios del cristianismo, encontramos viudas y huérfanos que daban asistencia a los cristianos encarcelados por su $\mathrm{fe}^{27}$. Ciertamente, los líderes también los visitaban, razón por la cual no deja de sorprendernos que las viudas, los huérfanos y los ancianos desempeñaran esa tarea.

Pasemos ahora a analizar algunos detalles importantes de la carta a los Filipenses, desde esta perspectiva.

\section{La carta a los Filipenses}

\subsection{Introducción a la carta}

La discusión sobre si Filipenses está conformada por una o tres $\operatorname{cartas}^{28}$, la vamos a dejar de lado. En este artículo nos concentramos en su discurso tal y como se encuentra en la redacción final, que aparece en el canon del Nuevo Testamento. Dado que Pablo no indica la ciudad donde se encuentra guardando prisión, la posibilidad que se asuma siempre será incierta. Las propuestas más comunes son Éfeso y Roma. Aunque también se ha propuesto Cesarea. Ahora bien, en cuanto a Roma y Éfeso, existen razones tanto a favor como en contra. No vamos a exponer todos los argumentos conocidos por los expertos en Filipenses; para ello, remitimos a los comentarios existentes. Aquí nos inclinamos por Éfeso. Nos convence su cercanía con Filipos, lo cual permite una comunicación fluida. Además, creemos que cuando Pablo escribió a los corintios sobre sus problemas en la cárcel de Asia Menor (2 Co 1,8-10), se refería a la experiencia de cuando escribió Filipenses. Cabe recordar que Éfeso está en Asia Menor. Pablo pudo

27. En la carta de Luciano de Samósata Cronio, cuando habla contra los cristianos, menciona esta práctica de asistencia a los presos, entre ellos, a las viudas y los huérfanos: "Y desde el amanecer se podía ver junto a la cárcel esperando grupos de ancianos, viudas y huérfanos..."; en Obras II. Sobre la muerte de Peregrino (Madrid: Gredos, 1990), p. 246.

28. Las tres cartas, llamadas A, B y C, serían: A: 4.10-20; B: 1.1-3.1; C: 3.2-4.9. 
contar su experiencia a los hermanos de Corinto, porque, aun cuando había sido condenado a muerte, la ejecución no tuvo lugar por alguna razón y salió libre (1 Co 15,32). Si escribió la carta en una cárcel de Roma, la habría escrito entre el 60 y 62, después de la carta a los Romanos. Si escribió en una cárcel de Éfeso, la fecha de la carta sería entre el 52 y 54, durante el reinado de Tiberio o el de Nerón.

Es importante señalar que Filipos era una colonia romana. Su ubicación era bastante estratégica, pues estaba atravesada por la Vía Egnatia, ubicada cerca del mar y tenía yacimientos de oro y plata. Sus habitantes eran ciudadanos romanos, griegos y tracios, siendo estos últimos la población nativa. Los romanos, señala Lilian Portefaix ${ }^{29}$, ocupaban los puestos oficiales y eran los principales empleadores de campesinos. También eran los mayores propietarios de esclavos, que abundaban en el campo. Por ser una colonia, la población incluía a veteranos de guerra, que habían arribado en distintas oleadas ${ }^{30}$. Se trataba de soldados que recibían tierras en pago por sus servicios en el ejército romano.

Los destinatarios de una carta escrita desde la prisión, residentes en una colonia romana, donde conviven con exmilitares del imperio romano, son importantes. Existe el riesgo de ser considerado cómplice por mantener amistad con un preso, considerado enemigo de la sociedad romana y de sus gobernantes. Pero no solo los destinatarios del escrito corrían peligro, sino también las personas cercanas que les daban ayuda, los visitaban o recibían correspondencia. Timoteo y Epafrodito eran los que estaban en una posición delicada y, por lo tanto, los que debían tomar precauciones cuando visitaban a Pablo en la prisión. En este sentido, llama la atención que la carta no mencione por su nombre a una persona. En efecto, cuando Pablo exhorta a Evodia y Síntique a tener el mismo sentir, alude a alguien, cuyo nombre se reserva, para que ayude a esas dos líderes a ponerse de acuerdo. Lo llama "mi compañero fiel", literalmente, "genuino compañero de yugo" ( $\gamma v \eta ́ \sigma \iota \varepsilon$ oú $v \gamma \varepsilon)^{31}$.

En un intento de reconstrucción retórica percibimos tres frentes o grupos de oposición a los ideales de Pablo y de la comunidad de Filipos. El primero es la sociedad romana, llamada aquí "torcida y perversa" $(2,15)$ por seguir valores no acordes con los proclamados por el evangelio de Pablo. El segundo es el grupo de predicadores que se distancia de Pablo por su forma extrema de predicar dicho evangelio (1,15-17), lo cual también lo ha llevado a la prisión. Y el tercero

29. L. Portefaix, Sisters Rejoice. Paul's Letter to the Philippians and Luke-Acts as Seen by First-century Philippian Women (Upsala: Tryckkontakt, 1988), pp. 59-67.

30. Ibid., p. 60.

31. Algunas versiones transcriben el nombre dando por sentado que se llamaba "Sícigo" (BJ), pero no contamos con nombres iguales en la antigüedad. Es más probable que aluda al compañero genuino, fiel o incondicional. 
son los judaizantes, que difieren aún más de este segundo grupo en cuando a la propuesta de salvación y sus requerimientos $(3,1)$. Los filipenses tienen que cuidarse del primero y del tercero. El segundo se encuentra en la ciudad donde Pablo guarda prisión.

Veamos ahora la situación de los destinatarios. La comunidad de Filipos, muy probablemente romana, ya que vive en esa colonia, también pasa por dificultades. Tal vez la policía romana la vigila y/o sus vecinos son muy hostiles por profesar

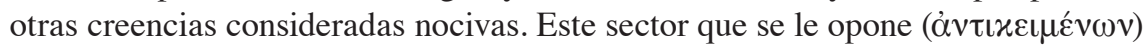
la intimida constantemente $(1,28)$. Por eso, sus miembros están muy preocupados y angustiados $(4,6)^{32}$. Por otro lado, si tomamos en cuenta lo que dice Hechos en 16,22-24, los filipenses seguramente guardaban memoria del terrible encarcelamiento sufrido por Pablo, justamente por presentar otra propuesta de vida diferente a la romana. Tal vez esa situación fortaleció los lazos de amistad y solidaridad con el apóstol. Al enterarse de que Pablo estaba detenido, le enviaron ayuda económica, ya que los presos dependían de amigos y familiares para sobrevivir, cosa que ellos saben bien. No era la primera vez que enviaban ayuda económica a Pablo. Este recuerda la solidaridad que tuvieron en más de una ocasión con él, desde que los había dejado, empezando con su estancia en Tesalónica (Fil 4,1516), cuando no estaba preso.

Posiblemente, la situación de la comunidad cristiana de Filipos se volvió más difícil a raíz de su solidaridad con Pablo encarcelado (1,7). La comunidad incluso envió a uno de sus miembros, Epafrodito, con dinero para las necesidades de Pablo en la prisión (4,10-19). Para colmo, Epafrodito enfermó muy gravemente y estuvo al borde de la muerte, ahí donde estaba Pablo $(2,27)$. Pablo les manda a Epafrodito, cuando ya está mejor. Es probable que él llevara la carta. A los filipenses les gustaría mucho que Pablo les enviara a Timoteo para fortalecerlos, pero eso le es imposible porque, en esos momentos, aquel le es imprescindible para su defensa, pues reina la incertidumbre en cuanto a si será condenado o liberado (1,23). Epafrodito les llevará noticias de Pablo.

La comunidad de creyentes en Filipos, liderada especialmente por mujeres, pasa también por divisiones internas. Dos grandes líderes, Evodia y Síntique, tienen algunos desacuerdos (4,3). Pablo las exhorta a ponerse de acuerdo, ayudadas por un mediador, un compañero de trabajo de mucha confianza

32. Recordemos que según Hch 16,22-24, años atrás, al inicio de la fundación de la comunidad, la gente de Filipos había acusado a Pablo y a Silas de hablar de costumbres inaceptables para los romanos. A causa de ese motín, las autoridades los mandaron desnudar, azotar severamente, meterlos en el cuarto más terrible de la cárcel y encadenarlos con un cepo (Hch 16,22-24). Seguramente los convertidos tenían ya este testimonio de Pablo en su mente, cuando supieron que nuevamente estaba preso, pero en Éfeso (o Roma). 
de Pablo (бú $v \gamma \varepsilon$ ), cuyo nombre se reserva, posiblemente para protegerlo de la censura ${ }^{33}$.

La correspondencia entre Pablo y la comunidad de Filipos es crucial para tener noticias de un lado y del otro lado, para dar alegría y aliviar un poco la tensión de la inseguridad. El apóstol se anima ( $\dot{v} \psi v \chi \hat{\omega})$, al recibir noticias de la comunidad $(2,19)$. Pablo utiliza unos vocativos muy amorosos hacia los filipenses: amados, añorados, mi corona, mi alegría, hermanos míos, etc. No es para menos, detrás hay una fuerte y sólida relación de amistad y lucha conjunta. Evodia y Síntique lucharon junto (бvví $\theta \lambda \eta \sigma o ́ v)$ a Pablo en lo referente al

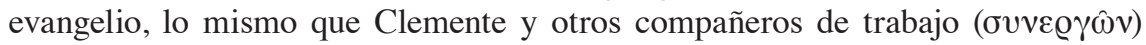
(4,2-3). La carta, como se puede ver, utiliza muchas imágenes militares, algunos han estudiado este aspecto de la carta. Para nosotros, eso es claro, pues tratándose de un prisionero político, su militancia política-religiosa sale a flote en su lenguaje metafórico.

Pablo, como un líder del movimiento del resucitado, que fue a dar a la cárcel por sus ideas y que ve que su postura también pone en peligro a las comunidades que lo escuchan, necesita escribir a los creyentes de Filipos no solo para agradecerles la ayuda económica, sino para consolarlos, fortalecerlos, tranquilizarlos, darles seguridad y exhortarlos a resistir y a permanecer unidos, defendiendo la causa del evangelio, a pesar de la oposición.

\subsection{Situación física y emocional de Pablo encadenado}

Pablo poco habla de sus sufrimientos en la prisión. Por eso, para hablar de su situación física debemos leer entre líneas y visualizarlo en la prisión. Según el análisis anterior, Pablo padece la custodia militar (custodia militaris), puesto que recibe visitas como las de Timoteo y Epafrodito y puede recibir dinero. Este tipo de custodia consistía en estar encadenado a uno o más soldados, ya sea por los brazos, las manos (manacles) o las piernas y los pies (pedicles), lo cual era bastante incómodo. La carta tuvo que haberla dictado o debió pagar al soldado para que lo liberara mientras la escribía. En su carta habla del pretorio. Si Pablo está en Éfeso, se trataría de un lugar dentro del palacio del gobernador. La prisión, indica Wansink, no solo se guardaba en edificios construidos expresamente para ello, sino que cualquier edificio podía funcionar como prisión para algunos. El extraño saludo al final de la carta "de los de la casa del césar", si no era una estrategia o código de Pablo para evadir la censura, se trataría de esclavos del gobernador, familiarizados con Pablo y tal vez también con Timoteo y Epafrodito. Esto nos hace pensar que tal vez estos le hicieron la vida menos dura en la prisión. En 1,17, Pablo no niega el sufrimiento en la prisión, al señalar que el grupo rival,

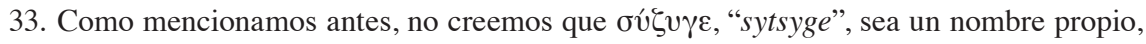
como algunos proponen. 
que predica por ambición personal, cree añadirle más sufrimiento a sus cadenas. Además, es muy probable que Pablo haya pasado hambre. En 4,12 indica que ha aprendido el secreto ( $\mu \varepsilon \mu u ́ \eta \mu \alpha \iota)$ de pasar hambre y no solo el de pasarla bien. La experiencia lo ha llevado a arreglárselas en cualquier necesidad $(4,11)$.

En cuanto a su situación emocional y psicológica, podemos percibir a través de la carta varias cosas: su fuerza en la debilidad, su experiencia de vivir en la incertidumbre respecto a la condena y su preocupación por sus destinatarios ante su ausencia y la hostilidad que enfrentan.

Su fuerza interior y su firmeza las podemos percibir en 1,20, cuando dice tener "la absoluta seguridad de que ahora y siempre, Cristo manifestará su gloria en mi persona, tanto si estoy vivo como si estoy muerto". En 2,17, cuando exhorta a los filipenses a que brillen en medio de la sociedad perversa $(2,15)$, afirma: "Y aunque tuviera que sufrir el martirio como ofrenda sacrificial en favor de la fe de ustedes, me sentiría dichoso compartiendo con todos ustedes mi alegría; alégrense igualmente de compartir conmigo su alegría”. Pablo está seguro de lo que cree y de sus ideales, siente la fuerza del Espíritu de Jesucristo $(1,19)$ y ha luchado por sus convicciones y su fe, y está dispuesto a dar la vida. La experiencia de Pablo encadenado nos ayuda a entender lo que había expresado a los corintios en su segunda carta: "Por eso me complazco en mis flaquezas, en las injurias, en las necesidades, en las persecuciones y las angustias sufridas por Cristo; pues, cuando estoy débil, entonces es cuando soy fuerte" (2 Co 12,10).

Uno de los problemas de las personas privadas de la libertad es el manejo del tiempo y de la incertidumbre respecto a lo que sucederá después del juicio. Pablo experimenta la situación de incertidumbre, no sabe si lo van a condenar a muerte o si lo pondrán en libertad. Él confía que saldrá libre por las oraciones en su favor $(1,19)$, tiene confianza en que eso puede suceder, si es que no lo dice para tranquilizar a sus destinatarios $(1,25 ; 1,26)$; aunque añora estar con Cristo, prefiere la libertad a la muerte para ayudar a la comunidad de Filipos $(1,22)$. Sin embargo, la reiteración de la posibilidad de la condena a muerte es más fuerte y pareciera que Pablo se prepara para ese desenlace: para él, dice, "la vida es Cristo y la muerte una ganancia" $(1,21 ; 2,17)$.

Pablo habla mucho de gozo. Esa voz y sus derivados se repiten dieciséis veces. Esta es una de sus estrategias para dar consuelo, fortaleza y esperanza a sus destinatarios. Sin embargo, tal como es de esperar, la tristeza no está ausente, incluso el deseo de morir. Esto es normal en prisioneros políticos. Pablo menciona la tristeza de la prisión cuando Epafrodito cae gravemente enfermo. Dios lo sana, dice en 2,27, por compasión, no solo hacia Epafrodito, sino también hacia él, "no queriendo añadir más tristeza ( $\lambda u ́ \pi \eta)$ sobre (mi) tristeza $(\lambda u ́ \tau \eta)$ ". Esta última se refiere a la tristeza de las cadenas. Ya mencionamos antes su deseo de estar con Cristo, es decir, de morir. Pero en ese caso, da la impresión de que trata de aceptar con valor la condena a muerte, la decisión en el juicio no depende 
de él. Sin embargo, en 1,22 hay algo interesante, que poquísimos exégetas han notado y que Wansink, después de su análisis de las prisiones en la antigüedad, lo hace ver. En ese versículo, Pablo no sabe qué escoger, si vivir o morir. La mayoría de los comentarios no toman en serio el sujeto activo del verbo, que literalmente dice: "Si el vivir en la carne esto para mí es fruto de trabajo (será

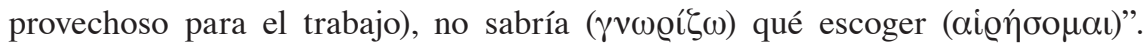
Esta frase concentra la decisión solo en Pablo, como sujeto activo de los verbos

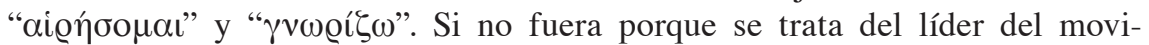
miento del resucitado, cualquiera pensaría que tiene en mente el suicidio, cosa frecuente en los prisioneros del tiempo del imperio romano, como vimos antes. Si queremos ver a Pablo como el sujeto del verbo elegir y tomar literalmente lo que dice, habría que pensar como Wansink en una muerte voluntaria pasiva. Esto significa que no se defenderá en el juicio, tal como se espera. Esto no está fuera de lugar, porque así imitaría a Jesús. En el juicio ante Pilato, según la versión de Mateo, Jesús decide guardar silencio y no defenderse de las acusaciones, lo cual propició la inmediata condena a muerte.

No obstante, lo que preocupa a Pablo, racional y emocionalmente, no es su situación, sino la de sus destinatarios, los filipenses, que se sienten intimidados y perseguidos, más por los romanos que por el grupo de los judaizantes. Su angustia mayor es su amada comunidad de creyentes de Filipos. El grueso de la carta lo dedica a animarlos, fortalecerlos, exhortarlos y aconsejarlos para que se mantengan firmes y fieles al evangelio, que conocen por medio de Pablo, lo cual exige adoptar una postura frente a los valores dominantes de la sociedad romana imperial. Por otro lado, Pablo se cuida en todo lo que dice en la carta para que pueda pasar la censura, procedimiento al cual eran sometidos todos los escritos que salían de la prisión. Por eso, no podía sentirse libre para expresar todo lo que deseaba, sino que tenía que escribir de manera opaca o ambigua, con la esperanza de que sus destinatarios entendieran lo que les decía entre líneas.

\subsection{La teología que surge de su experiencia como prisionero}

La dialéctica de gracia y praxis no es contradictoria en Pablo. Todo depende de Dios, pero eso no excusa luchar para defender el evangelio. Al igual que cualquier otro judío, Pablo cree que todo ocurre por voluntad de Dios y, en su caso particular, en la prisión, esta creencia es aún más fuerte. Podríamos decir que la dependencia de Dios es absoluta; el estar encadenado y el sentirse impotente, lo exige ${ }^{34}$. Dios está en todo: los filipenses son excelentes colaboradores en la proclamación y defensa del evangelio, pero es Dios quien ha comenzado y perfeccionado esa obra en ellos $(1,6)$; la salvación es algo por lo que se trabaja

34. En prisioneros políticos como Bonhoeffer, Hillesum, Frei Betto, Mandela, Karl Gaspar y otros. 
con vistas a que todos la alcancen, pero es Dios el que actúa en el querer y el hacer (2,12-13); por la obra de Cristo se arriesga la vida, como lo ha hecho también Epafrodito al solidarizarse con Pablo (2,30). Pablo ha ganado a Cristo, porque fue encontrado por Cristo $(3,9)$. Aquí se ubica el debate con los judaizantes, que depositan su confianza en la propia ley, en su identidad cultural, que consideran superior a las demás. Eso no es lo importante para Pablo. De hecho, ya lo ha dejado atrás $(3,5-7)$ y ha optado por otra manera de ser y de vivir, donde Jesucristo reina como soberano de una manera diferente a la del emperador, sobre todo, en relación a sus súbditos o vasallos, los ciudadanos romanos.

El gobierno de Jesucristo se fundamenta en la justicia de la gracia, donde la misericordia prima en el juicio de Dios. De manera que Pablo decidió orientar su vida, su práctica y sus actitudes guiado por un horizonte más amplio, que lo lleva a depender absolutamente de la gracia de Dios, en medio de la hostilidad y la muerte. La fuerza que lo ayuda a seguir dentro de ese horizonte es el modelo de la vida de Jesucristo, reflejada en el himno cristológico de 2,6-11, posiblemente prepaulino. Según el himno, Jesús padeció todas las cosas peores que un ser humano puede padecer: se hizo esclavo, se dejó humillar y fue condenado a la muerte en la cruz, la muerte peor y la más humillante, en tiempo del imperio. Pero el juicio de Dios fue diferente al de las leyes romanas y lo reivindicó: lo exaltó en extremo, lo puso como Señor del universo y de esa manera le quitó la autoridad a todos los poderes de la tierra. Así, la vida, la muerte y la resurrección de Jesucristo le dan razón de su existencia en la prisión. Ese es su gran anhelo, el poder de la resurrección del crucificado es lo que le da la fuerza para seguir vivo, pues él también espera resucitar de entre los muertos (11). Pablo se mueve y resiste

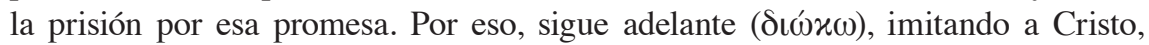
intentando ser como él, buscando ser íntegro en su plenitud ( $\tau \varepsilon \lambda \varepsilon \iota o ́ \omega)(3,12)$.

Esta forma de convivir, llamada ciudadanía celestial, hace que valga la pena luchar por ella en contra de la corriente dominante. Implica dejar lo que es valioso a la luz de la sociedad judía (ley, circuncisión) y romana (banquetes y otras cosas materiales), y lanzarse hacia adelante, como al vacío $(3,13)$. Pablo lo hizo, pues está seguro de que llegará a la meta, como un atleta que se concentra en el trofeo al final de su carrera (13.14).

Por eso hay que ver la gracia de Dios en el padecimiento de las cadenas. En su cuerpo encadenado, Cristo es engrandecido $(1,20)$; el crucificado se hace presente, porque él es la causa de que esté preso. Pablo siente en carne propia la solidaridad del crucificado, en su padecimiento en la cárcel, por eso dice: “... quiero compartir sus padecimientos y conformar mi muerte con la suya" $(3,10)$. No por un sentido masoquista, sino porque Pablo se ha aferrado a la promesa de la resurrección. De hecho, eso es lo que más anhela. En el mismo versículo expresa: "Quiero conocer a Cristo, experimentar el poder de su resurrección", y en el siguiente (11): "Espero así participar de la resurrección de entre los muertos". 
Pablo vive y actúa con la fe de que pronto llegará el verdadero Salvador y el sufrimiento tendrá su fin, pues "el Señor está cerca" $(4,5)$. Por eso se aguarda

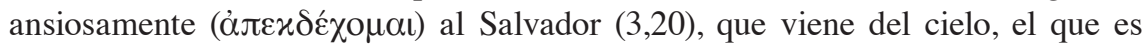

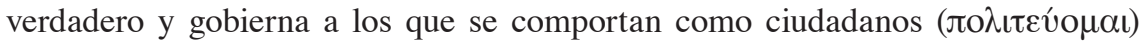
dignos del evangelio $(1,27)$. Ellos son los que comparten la ciudadanía que vale a los ojos de Dios $(3,20)$. Esta ciudadanía ( extraterrestre, sino otra manera de vivir y de ser aquí en la historia, opuesta a la ciudadanía romana ${ }^{35}$, una ciudadanía que se vive a la espera del final de los tiempos. Dos veces aparece "el día de Cristo", en alusión al fin de la historia, y las dos tienen que ver con la praxis que será juzgada. La primera se refiere a la práctica que los filipenses comenzaron y que Dios perfeccionará hasta el final $(1,6)$; la otra aparece dentro de la exhortación a los filipenses para que sean luz en medio de la sociedad perversa y para que mantengan firmes la palabra de vida, para que, en "el día de Cristo", Pablo salga airoso y quede al descubierto que no trabajó por el evangelio en vano $(2,15-16)$. Por lo pronto, él quiere ser como Cristo, con la esperanza de que su cuerpo encadenado, vergonzoso y humillado a los ojos de la sociedad, sea transformado por el gran poder en un cuerpo glorioso $(3,21)$. Esa será la reivindicación que el Señor hará con Pablo y esa esperanza es la que lo ayuda a resistir los sufrimientos y las humillaciones de la prisión.

\subsection{Exhortaciones a los destinatarios}

Los destinatarios son probablemente en su mayoría mujeres, grandes líderes y valientes $^{36}$. Ellas, junto con otros líderes varones, como Clemente y el misterioso amigo fiel, se encuentran al frente de la comunidad cristiana de Filipos. Están angustiadas por la situación de Pablo en la prisión y por el peligro que corre Epafrodito, tanto por su enfermedad como por visitar a un preso "político". Hacen un gran esfuerzo para poder solidarizarse económicamente con él, porque es una comunidad con pocos recursos. También, dijimos, la comunidad está siendo intimidada por gente del lugar, que se opone al evangelio proclamado por ella. Posiblemente, la hostilidad viene también porque se rehúsan a dar culto al césar y porque proponen otra conducta, que choca con su forma de conducirse. Pablo se angustia por ellos. En su carta, se esfuerza para tranquilizarlos y consolarlos: "No se preocupen..." ( $\mu \varepsilon \varrho \iota v \alpha ́$ ć) (4.6), les dice, el término griego refiere a la preocupación y la ansiedad que ocurre cuando se percibe un daño o desgracia. Por eso, les asegura que Dios les va a dar una paz más allá de toda comprensión y de toda lógica (4,7). Pablo insiste en que tomen con alegría esa

35. R. Cassidy, Paul in Chains, o. c., pp. 194-195.

36. Portefaix escribe su libro Sister Rejoice, o. c., desde la teoría de la recepción de los textos literarios, y su lectura la orienta desde el punto de vista de la recepción de las mujeres de Filipos. Ella analiza el trasfondo cultural y religioso de las mujeres de Filipos, porque considera que eran ellas las principales destinatarias de la carta. 
dura situación y los exhorta a no desfallecer en la opción que han hecho por el evangelio de Jesucristo, pues el Dios de paz los acompañará $(4,9)$.

Además de exhortarlos a que se alegren, el apóstol les suplica que se mantengan firmes $(\sigma \tau \eta ́ \gamma \varepsilon \tau \varepsilon)(1,2 ; 4,1)$ y, sobre todo, que permanezcan unidos, teniendo el mismo pensamiento $(\phi \varrho o v \varepsilon ́(\omega)$. Desde el primer capítulo, Pablo recalca la unidad en la exhortación con diferentes términos. En 1,27, los exhorta: "estén

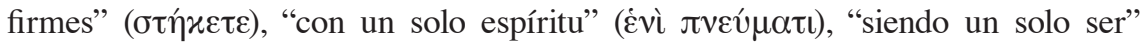

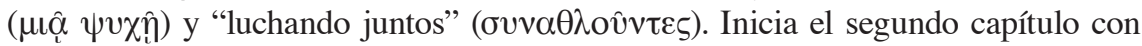
gran solemnidad (2,1-2), rogándoles de nuevo que estén unidos. La unidad es tan importante para él que lo colmaría de una gran alegría si tienen un mismo sentir o

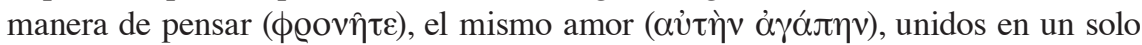

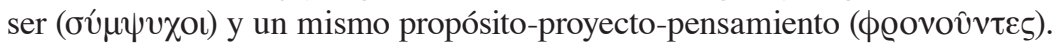

Tener el mismo sentir y pensar apunta al evangelio, que aquí llama "palabra de vida" $(2,16)$. Es esta palabra la que deben mantener o creer con firmeza

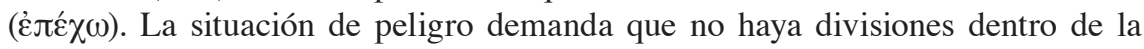
comunidad; por eso, Evodia y Síntique deben buscar la reconciliación y ponerse de acuerdo, a lo cual el contacto de confianza de Pablo (el amigo fiel) puede ayudarlas $(4,3)$. Hay que evitar las quejas $(\gamma \circ \gamma \gamma v \sigma \mu \hat{\omega} v)$ y las argumentaciones $(\delta\llcorner\alpha \lambda o \gamma \iota \sigma \mu \hat{\omega} v)$ en el seno de la comunidad $(2,14)$ para no debilitarse como movimiento unido y ser más vulnerables ante los adversarios. Hay que tratar de

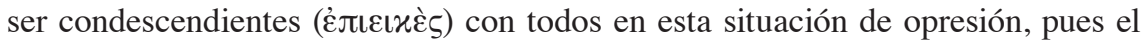
Señor está cerca $(4,5)$.

Además de mantener el espíritu alto, alegrarse, estar unidos y mantenerse firmes en sus creencias, Pablo los exhorta a estar atentos, a discernir para

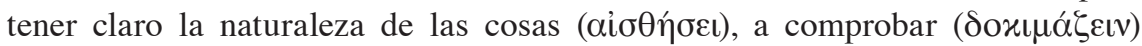
ellos mismos lo que verdaderamente importa, lo que hace la diferencia ( $\tau \grave{\alpha} \delta \iota \alpha \phi \varepsilon ́ \varrho o v \tau \alpha$ ), a ser intachables y puros, y llenos de frutos de justicia

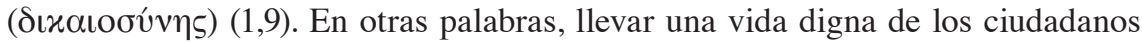
$(\pi \circ \lambda \iota \tau \varepsilon v ́ \varepsilon \sigma \theta \varepsilon)(1,27)$ del señorío de Jesucristo. No deben imitar a quienes piensan solo en sí mismos y en sus propios intereses y placeres, los romanos, llamados aquí "enemigos de la cruz" $(3,18)$, cuyo modelo de vida es el emperador (en este caso, sería Nerón) y cuyos súbditos los persiguen u hostigan $(1,28)$. Al contrario, deben comportarse como hijos de Dios, irreprochables, para así ser estrellas o antorchas en medio de "una generación torcida y perversa" $(2,15)$.

Las oraciones y súplicas tanto de Pablo como de la comunidad de Filipos son fundamentales para cobrar fuerzas y poder resistir a quienes causan el sufrimiento $(1,4.19 ; 4,6)$. Pablo recuerda con realismo a los filipenses que ellos también pueden padecer, pues libran la misma lucha que él (1,29-30). De allí las exhortaciones a la unidad, al amor, a mantenerse firmes, a luchar juntos y a tener un mismo objetivo. El Espíritu del resucitado (1,19), el Cristo $(4,13)$, es quien da la fuerza en todo para seguir adelante. 


\section{Cartas de prisión como género epistolar}

Hoy en día contamos con cartas escritas desde la prisión, a lo largo del siglo $\mathrm{XX}$. Entre la gente conocida mundialmente, que fue encarcelada por sus ideas y que escribió cartas desde su fe cristiana o desde la resistencia ante las injusticias de su sociedad, tenemos a Dietrich Bonhoeffer (detenido desde 1943 hasta su ejecución en 1945), miembro del grupo de resistencia contra la dictadura de Hitler; Etty Hillesum (joven judía que escribió cartas desde un campo de concentración en Holanda; Frei Betto (detenido desde 1969 hasta 1973), dominico encarcelado por su resistencia contra la dictadura de Brasil; Karl Gaspar, de la orden de los redentoristas, detenido durante la dictadura de Marcos en Filipinas; y Nelson Mandela (encarcelado desde 1964 hasta 1990), líder de la resistencia contra el apartheid de Sudáfrica.

Al leer las cartas de estas personas, encontramos ciertas constantes, que nos hacen pensar en la posibilidad de contar con otro género literario, catalogado como cartas desde la prisión. La carta a los Filipenses ha sido clasificada como "carta de amistad" o "carta de amistad y finanzas" ${ }^{37}$, de acuerdo a la tipografía de la epistolografía romana. Sin embargo, no nos parece suficiente, porque no toma seriamente en cuenta el contexto desde donde se escribe y la experiencia del prisionero. Por eso, es necesario proponer un nuevo tipo de carta, "cartas desde la prisión". Se trataría de cartas escritas por personas encarceladas por sus ideas, es decir, por pensar de forma diferente al statu quo. Se trataría de cartas de prisioneros políticos, pero no solo políticos, sino también de prisioneros comunes, encarcelados injustamente.

Bonhoeffer, Hillesum, Mandela, Gaspar y Frei Betto hablan desde una gran fuerza interior, relativizan las cosas materiales, viven en la incertidumbre acerca de su condena y juicio, constantemente se preocupan más por los que están afuera, los aconsejan, teologizan a partir de su experiencia de estar privados de libertad y de su posible fin, y están dispuestos a morir por sus ideales.

La intertextualidad, el leer y escuchar cartas de otros prisioneros políticos, ayuda a comprender con mayor profundidad el mensaje de Pablo, un prisionero por causa del evangelio.

37. Alexander Loveday (1989), Ben Witherington (1994), Gordon Fee (1995) y otros. 